\title{
Fairness in heart allocation
}

\author{
John V. Conte, MD
}

\author{
From the Division of Cardiac Surgery, Department of Surgery, The Johns Hopkins Hospital, Baltimore Md. \\ Disclosures: Author has nothing to disclose with regard to commercial support. \\ Received for publication Aug 6, 2016; accepted for publication Aug 8, 2016; available ahead of print Sept 15, \\ 2016. \\ Address for reprints: John V. Conte, MD, Division of Cardiac Surgery, Zayed Tower, Suite 7107, The Johns \\ Hopkins Hospital, 1800 Orleans St, Baltimore, MD 21287-4618 (E-mail: jconte@jhmi.edu). \\ J Thorac Cardiovasc Surg 2016;152:1487-8 \\ 0022-5223/\$36.00 \\ Copyright (C) 2016 by The American Association for Thoracic Surgery \\ http://dx.doi.org/10.1016/j.jtcvs.2016.08.008
}

Fairness. Fairness is defined by the Merriam-Webster dictionary as "marked by impartiality and honesty." 1 Fairness is what everyone-from patients and health care practitioners to the general population and even politicians-would want for the organ allocation system in the United States. Fairness is what was sought in 1984 when the United States government created the Organ Procurement and Transplant Network (OPTN) to devise a framework to guide organ allocation in this country. Fairness is what has been the goal of each physician has sought when the changing realities brought about by medical advances and technical innovations have required changes to the OPTN rules for organ allocation. The ideal allocation system would reduce waiting list mortality, optimize posttransplant, outcomes and provide equal access to donor organs. Seems simple.

In this issue of the Journal, a noted expert in the field of heart transplantation, Dr Joseph Rogers ${ }^{2}$ from Duke University, describes the changes proposed by the OPTN and United Network for Organ Sharing (UNOS) Thoracic Organ Transplantation Committee (TOTC) to the heart allocation system in the United States. He delves into the reasons that changes were needed and the methodology used to arrive at the proposal, and he presents a realistic discussion of the strengths and weaknesses of the proposal.

By 2012, it was acknowledged that the rules adopted in 2006 were found to be inadequate to guide the allocation of hearts for transplantation in the United States. The OPTN/UNOS TOTC studied the issue thoroughly and decided that changes were needed. Although they are widely considered an improvement over the rules adopted in 1999, the 2006 rules nonetheless have resulted in an allocation system with the following disadvantages: (1) There were too many patients in the highest urgency class (1A), which diminished its ability to truly differentiate urgency. (2) The system required too many patients to be granted exceptions to be listed in a higher urgency status. (3) Gaming the system was commonplace, and frank cheating did occur. (4) The system could not accommodate the increased use of mechanical circulatory support and its complications. (5) Finally, the system maintained a

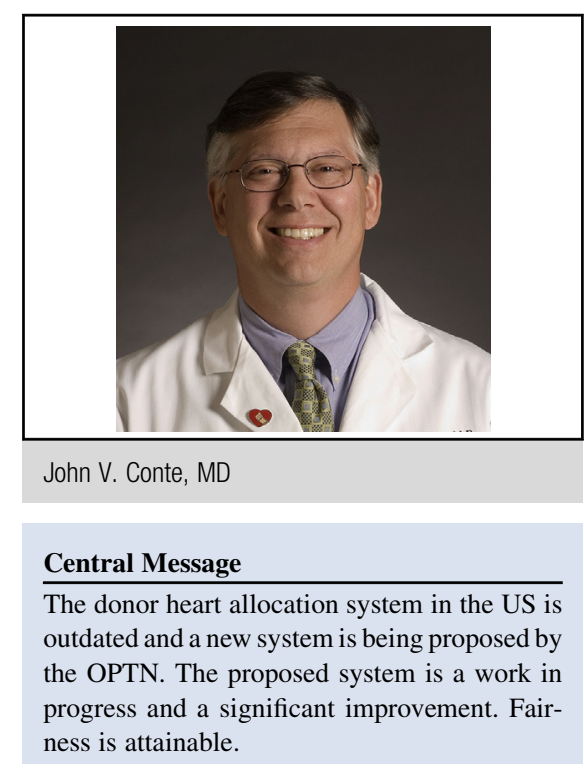

See Article page 1484.

geographic disadvantage to programs in remote areas, on either coast, or on the northern or southern borders.

Consideration was given to the development of a heart-specific allocation score such as is used in other solid organ transplants, but the OPTN/UNOS TOTC decided that there were insufficient data to develop a workable system. The complexity and heterogeneity of heart failure and its treatments and the need to allow appropriate consideration of all of the factors that affect posttransplant survival will make this a challenging task. The development of a heart allocation score must include this, and it will remain the "holy grail" of a heart allocation system. This has to be the next step in donor heart allocation. Until then a new system is necessary.

The current OPTN/UNOS TOTC proposal adds more recipient categories, rising to 6 from 3 , and provides for broader geographic sharing of donor hearts as far as 1000 miles from the donor center. The new system was validated by extensive modeling with a thoracic simulation allocation model with data from the Scientific Registry of Transplant Recipients. The proposed changes are expected to lower waiting list mortality rates overall and achieve higher transplant rates for the most medically urgent candidates without increasing overall posttransplant mortality or increasing waiting list mortality for candidates in lower urgency statuses.

The proposal was submitted for public comment from January to March 2016, and the full proposal and comments 
can be seen at the OPTN/UNOS website. ${ }^{3}$ Valuable insights and comments were shared. Several key points need to be considered.

The use of extracorporeal membrane oxygenation and other high-risk support modalities historically has reduced posttransplant survival, and many of the public comments have pointed this out and raised concern about the possibility of overuse of certain technologies to improve chances of receiving an organ at the expense of inferior outcomes. Gaming the system is still possible.

Longer distances and longer ischemic times may affect organ function. This will be particularly important when transplanting sicker patients. The geographic areas are arbitrary and not population based. This may require tinkering down the road, as will provisions for highly sensitized patients and patients with unusual problems, such as ventricular arrhythmias and certain types of hypertrophic cardiomyopathies among others. Clearer definitions of mechanical circulatory support complications and the related transplant urgency need to be established, and combined heart-lung transplants still represent an allocation challenge.

Organ procurement costs will inevitably go up.
What it does not do is change the behavior of programs in making organ acceptance decisions. Perhaps there should be some consideration for standardizing organ acceptance and perhaps for basing program certification on maintaining a certain level of organ acceptance and utilization. Could mandatory acceptance of matched hearts be in the future?

Many people are trying to make the US heart allocation system a fair and data-driven system. We are getting there. A new proposal will be out for public comment in the autumn of 2016 and will incorporate many of the comments and suggestions made. It will not be perfect and should be considered an intermediate step toward a heart allocation score, which should be the ultimate goal. This system is an improvement and should be supported when it is finalized. We will be closer to "fair" than ever before.

\section{References}

1. Merriam-Webster. Fairness. Available at: http://www.merriam-webster.com/ dictionary/fairness. Accessed July 26, 2016.

2. Rogers J. Changes in us heart allocation: a community energized to improve policy. J Thorac Cardiovasc Surg. 2016;152:1484-6.

3. US Department of Health \& Human Services. Organ Procurement and Transplantation Network: adult heart allocation changes 2016. Available at: https://optn. transplant.hrsa.gov/governance/public-comment/adult-heart-allocation-changes2016/. Accessed July 26, 2016. 